Nat. Hazards Earth Syst. Sci., 18, 491-497, 2018

https://doi.org/10.5194/nhess-18-491-2018

(C) Author(s) 2018. This work is distributed under the Creative Commons Attribution 3.0 License.

\title{
Brief communication: Drought likelihood for East Africa
}

\author{
Hui Yang ${ }^{1,2}$ and Chris Huntingford ${ }^{2}$ \\ ${ }^{1}$ Department of Ecology, School of Urban and Environmental Sciences, Peking University, Beijing, 100871, PR China \\ ${ }^{2}$ Centre for Ecology and Hydrology, Wallingford, Oxfordshire, OX10 8BB, UK
}

Correspondence: Hui Yang (yang_hui@pku.edu.cn)

Received: 10 May 2017 - Discussion started: 2 June 2017

Revised: 1 December 2017 - Accepted: 17 December 2017 - Published: 14 February 2018

\begin{abstract}
The East Africa drought in autumn of year 2016 caused malnutrition, illness and death. Close to 16 million people across Somalia, Ethiopia and Kenya needed food, water and medical assistance. Many factors influence drought stress and response. However, inevitably the following question is asked: are elevated greenhouse gas concentrations altering extreme rainfall deficit frequency? We investigate this with general circulation models (GCMs). After GCM bias correction to match the climatological mean of the CHIRPS data-based rainfall product, climate models project small decreases in probability of drought with the same (or worse) severity as 2016 ASO (August to October) East African event. This is by the end of the 21 st century compared to the probabilities for present day. However, when further adjusting the climatological variability of GCMs to also match CHIRPS data, by additionally bias-correcting for variance, then the probability of drought occurrence will increase slightly over the same period.
\end{abstract}

Historical rainfall estimated by Climate Hazards Group InfraRed Precipitation with Station data (CHIRPS; Funk et al., 2015) shows that, during August to October (ASO) of 2016, large parts of Somalia, Ethiopia and Kenya (black rectangle, Fig. 1a) had a reduction of $40 \%$ or more in rainfall compared to a baseline ASO period 1981-2015. For this region, the spatial average of monthly rainfall during ASO of 2016 lies at least 1 standard deviation (SD) below the climatological mean of the other years (Fig. 1b). The year of 2016 is the driest year in the past four decades. Other years with rainfall at least $1 \mathrm{SD}$ below the climatological mean during 1981-2015 are 1983-1986, 1990 and 1991. We concentrate on East Africa, as this region experienced particularly poor harvest and famine was widely reported during 2016 (noting that many regions outside the black rectangle of Fig. 1a also experienced major rainfall deficits in 2016). East Africa is especially vulnerable to the impacts of drought (DEC, 2017). The region has long experienced widespread poverty and high levels of food insecurity (Von Grebmer et al., 2016). The high dependence of its population on rain-fed agriculture, sometimes in tandem with political changes, exacerbates the impacts of droughts (Love, 2009; Masih et al., 2014).

To assess any influence of increasing atmospheric greenhouse gas concentrations, we use monthly rainfall data from 37 general circulation model (GCM) simulations for the historical period and for the high-emission future scenario RCP8.5. These are from the Coupled Model Intercomparison Project Phase 5 (CMIP5, Taylor et al., 2012). A summary of the main characteristics of the models is provided in Table S1 in the Supplement. A bias correction with two postprocessing steps is applied to the GCM precipitation estimates. We first calculate modelled and CHIRPS-based mean ASO rainfall estimates over the East Africa region (set as within black rectangle, Fig. 1a) and during the period 19812015. The GCM precipitation mean ASO estimates, both past and future, are corrected for each model year by a GCMspecific mean correction factor. This factor is a ratio of the climatological mean of each GCM to that of the CHIRPS product as

$x_{\text {corr }, i, j}^{\mu}=x_{\text {model }, i, j} \times \frac{\mu_{\text {obs }}}{\mu_{\text {model }, j}}$.

Here $x_{\text {model }, i, j}$ and $x_{\text {corr }, i, j}^{\mu}$ are, respectively, model simulated and mean bias-corrected ASO precipitation data of the $i$ th year $(i=1,2, \ldots, 31)$ for the $j$ th $\operatorname{GCM}(j=1,2, \ldots, 37)$. $\mu_{\text {obs }}$ and $\mu_{\text {model }, j}$ are the observed and GCM-specific time mean (i.e. average across indices $i$ ) of ASO rainfall estimates during the period 1981-2015. Second, we then adjust 


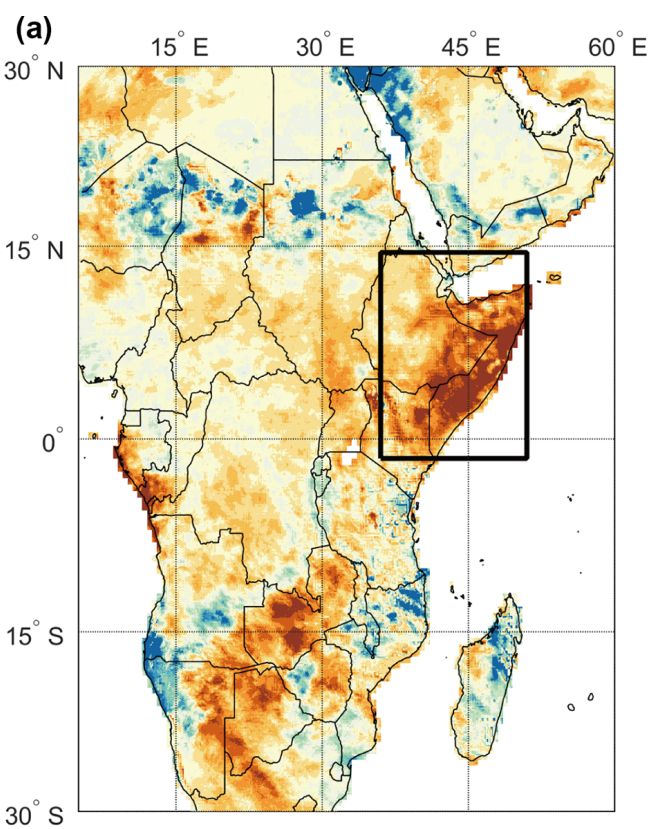

Rainfall for Aug to Oct 2016 as a percent change from average (\%)

(b)

(c)

(d)
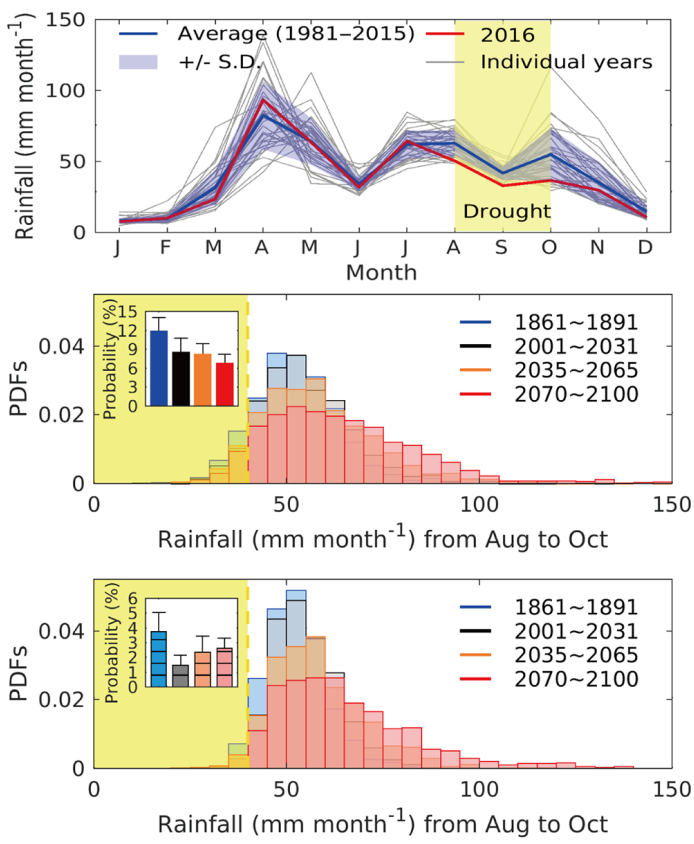

Figure 1. (a) Black rectangle is the location of the study region $\left(14.5^{\circ} \mathrm{N}-1.5^{\circ} \mathrm{S}, 36-51^{\circ} \mathrm{E}\right)$. Plotted is mean rainfall for 2016 and months August to the end of October (ASO), presented as relative change (as \%) to the long-term average ASO values (1981-2015). Values based on CHIRPS precipitation product. (b) CHIRPS-based monthly total rainfall ( $\mathrm{mm} \mathrm{month}{ }^{-1}$ ) over study region (panel a; land within black rectangle) for years 1981 to 2016 . Year 2016 is red, other years are individual grey lines, and multi-year average (not including 2016) is the blue line. Blue shading is \pm 1 SD of monthly rainfall across years 1981-2015. The drought event of 2016 is defined as the three consecutive months of ASO (yellow shading), and noting rainfall in that year is below blue shading in these months. (c) CMIP5-based probability density functions (PDFs; binned to $5 \mathrm{~mm} \mathrm{month}^{-1}$ intervals) of mean ASO rainfall for periods 1861-1891 (blue), 2001-2031 (black), 2035-2065 (orange) and 2070-2100 (red). Each curve corresponds to combined estimates from 37 CMIP5 GCMs, with each GCM forced by historical emissions and RCP8.5 future scenario. Individual GCM mean bias correction is based on the CHIRPS precipitation product. Yellow shading is mean ASO rainfall less than $40 \mathrm{~mm} \mathrm{month}^{-1}$, which is the CHIRPS 2016-based threshold (mean of ASO, red curve in panel b). Inset shows probabilities of mean rainfall of ASO falling below the threshold for the same modelled periods (colours match those of curves and legend). The error bars are 2 SD (estimated via bootstrapping $80 \%$ replications from the 37 GCM precipitation data for the 31 -year periods). (d) Same as (c), but based on the mean- and variance-corrected GCM rainfall estimates.

the mean-corrected data from Eq. (1), such that they further are corrected to have an identical SD to the CHIRPS product whilst maintaining the bias correction for the mean. This gives bias-corrected estimates $x_{\mathrm{corr}, i, j}^{\mu, \sigma}$ as

$x_{\mathrm{corr}, i, j}^{\mu, \sigma}=\left(x_{\mathrm{corr}, i, j}^{\mu}-\overline{x_{\mathrm{corr}, j}^{\mu}}\right) \times\left(\frac{\sigma_{\mathrm{obs}}}{\sigma_{\mathrm{corr}, j}^{\mu}}\right)+\overline{x_{\mathrm{corr}, j}^{\mu}}$,

where $\overline{x_{\text {corr }, j}^{\mu}}\left(=\mu_{\mathrm{obs}}\right)$ is the 31-year average of mean biascorrected data from Eq. (1). $\sigma_{\mathrm{obs}}$ and $\sigma_{\mathrm{corr}, j}^{\mu}$ are SDs of the ASO rainfall estimates during the period 1981-2015 from observations and from the mean bias-corrected precipitation data created by Eq. (1). The adjustment of spread of rainfall distribution to match measurements is an important additional procedure to further constrain GCM estimates (Sippel et al., 2016; Jeon et al., 2016; Angélil et al., 2017). Together Eq. (1) ensures all GCMs have the CHIRPS-based mean, and with Eq. (2) also CHIRPS-based SD for the period 19812015. Histograms of bias-corrected mean ASO rainfall are presented in Fig. 1c for mean bias correction, and in Fig. 1d for mean and SD bias correction. These are derived from $37 \mathrm{GCMs}$, and for four 31-year periods (representing preindustrial, present-day and two future periods as marked). All GCMs are considered equally plausible.

We estimate the probability, in any year, of mean rainfall being less than $40 \mathrm{~mm}$ per month and during AugustOctober period. This threshold is $25 \%$ less than the climatological ASO mean and is the ASO CHIRPS estimate of mean rainfall level in the year 2016 drought (red curve within yellow highlight, Fig. 1b). For the mean-corrected GCM estimates, we compare (inset, Fig. 1c) the modelled period 1861-1891, representative of pre-industrial, with present day (period 2001-2031), and find this probability decreases slightly from $11.9 \%(2 \mathrm{SD} \pm 2.2 \%)$ to $8.6 \%(2 \mathrm{SD} \pm 2.2 \%)$. 

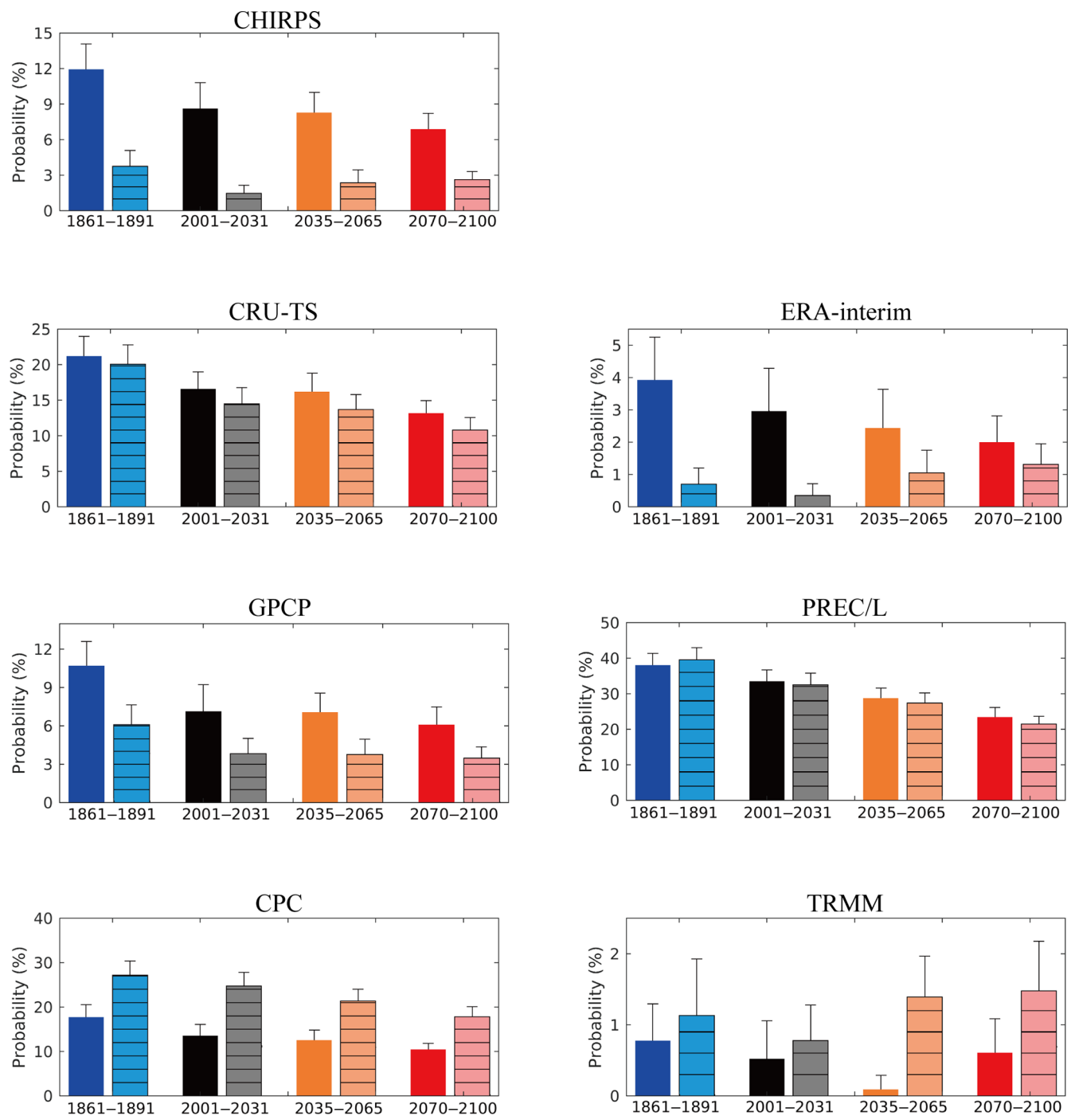

Figure 2. CMIP5 GCM-based histograms of probabilities of mean ASO rainfall falling below year 2016-based threshold values. This is for different time periods and for different observation-based precipitation product of CHIRPS, CRU-TS, ERA-interim, GPCP, PREC/L, CPC and TRMM. Shown for years 1861-1891 (blue), 2001-2031 (black), 2035-2065 (orange) and 2070-2100 (red), and using GCM simulations corresponding to historical and RCP8.5 estimates. Individual GCM projections are bias-corrected by the (panel-specific) precipitation product. These data are combined to give single overall probabilities across the 37 GCMs sampled. The histogram bars without horizontal hatching (left) are for the mean-corrected GCM precipitation estimates. The bars with hatching (right) are for the mean- and variancecorrected GCM estimates. The error bars are 2 SD (estimated via bootstrapping $80 \%$ replications from the 37 GCM precipitation data for the 31-year periods). Data in the CHIRPS panels repeat those of the insets of Fig. 1c and d.

The 2 SD values are estimated via bootstrapping with $80 \%$ replications from the 37 GCM precipitation data and for the 31-year periods. These trends continue, giving probabilities $8.3 \%( \pm 1.7 \%)$ and $6.9 \%( \pm 1.3 \%)$ for periods 2035 2065 and 2070-2100 respectively. However, for the meanand variance-corrected GCM estimates (Fig. 1d and inset), we find the probability of East African drought is smallest at present $(1.5 \% \pm 0.7 \%$, period 2001-2031). This probability becomes larger in the future, giving values of $2.4 \%$ $( \pm 1.1 \%)$ and $2.6 \%( \pm 0.7 \%)$ for periods $2035-2065$ and 2070-2100 respectively. Hence we find that additionally ac- counting for model biases in the variance, GCM distributions suggest a potential to significantly alter the predictions of drought events occurrence over East Africa, and for higher extreme frequency as the 21 st century progresses.

Large uncertainty in the observation-based precipitation products has been well reported (Angélil et al., 2016), and so we additionally use six other precipitation estimates (CRUTS, ERA-interim, GPCP, PREC/L, CPC and TRMM) to biascorrect GCM estimates. The probability of drought occurrence is based on estimates of ASO rainfall in 2016 for each individual dataset (values in Table S2). There are substan- 


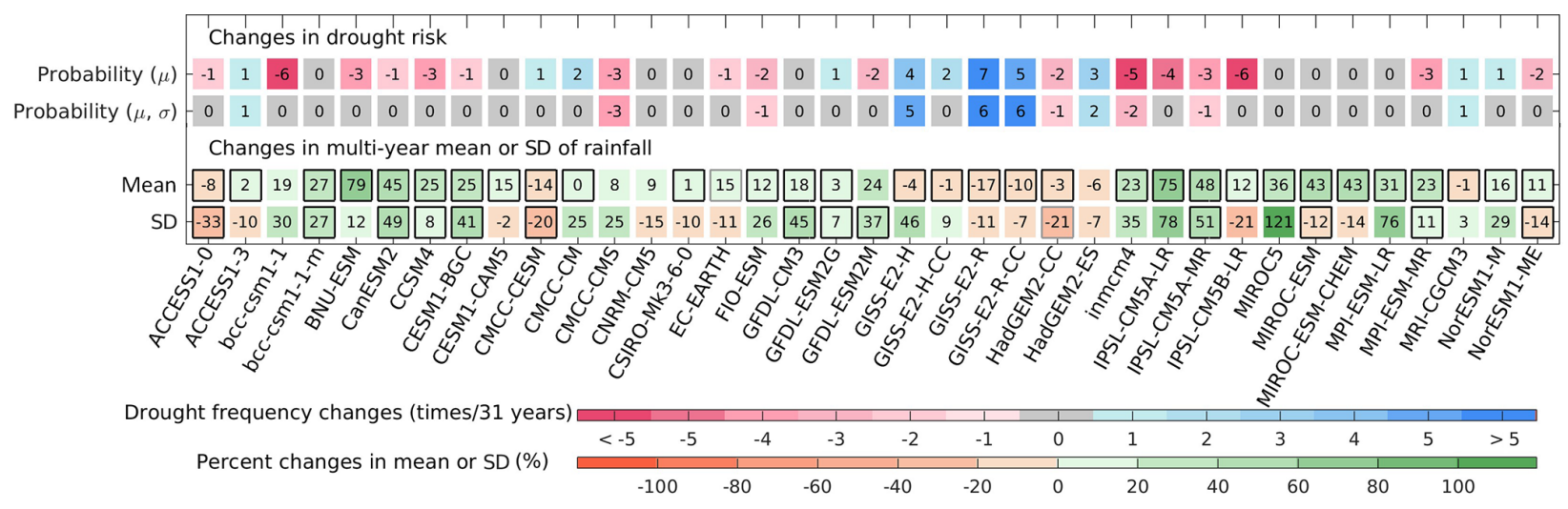

Figure 3. Rows 1 and 2 are changes in drought frequency (times per 31 years; top colour bar), for two methods of bias removal (meancorrected only marked as " $\mu$ " and mean and SD corrected as " $\mu, \sigma$ "). This is for each of the 37 GCMs as labelled, and comparing the difference between the present period of 2001-2031 and period 2070-2100. GCM bias correction and 2016 ASO rainfall threshold are from the CHIRPS rainfall product. Rows 3 and 4 show the GCM-based changes in multi-year mean and SD of ASO rainfall respectively, and between the same periods as top rows (bottom colour bar). Black borders indicate statistically significant differences in the 31-year rainfall mean between these two periods (row 3, $t$ test, with $P<0.05$ ) and significant difference in SD of GCM projections (row $4, F$ test, with $P<$ 0.05). Light grey borders in row 3 and row 4 indicate statistically significant difference at $5-10 \%$ significance level $(0.05 \leq P<0.1)$. Values in the third and fourth rows are the percentage changes in 31-year mean and SD of rainfall as $\left[\left(\overline{x_{\text {corr }, 2070-2100, j}^{\mu, \sigma} / x_{\text {corr }, 2001-2031, j}^{\mu, \sigma}}\right)-1\right] \times$ $100 \%$ and $\left[\left(\sigma_{\text {corr, } 2070-2100, j}^{\mu, \sigma} / \sigma_{\text {corr,2001-2031,j }}^{\mu, \sigma}\right)-1\right] \times 100 \%$, respectively. Here overbar is time-averaging over period of interest.

tial differences between these values. We use each of these extra datasets to repeat the bias correction of every GCM by the same algorithm of Eqs. (1) and (2) but now with new data-specific $\mu$ and $\sigma$ values. These $\mu$ and $\sigma$ quantities are given in Table S2. In Fig. 2 (first panel) we reproduce the insets of Fig. 1c (no hatching) and Fig. 1d (hatching) for CHIRPS, and then for the six other precipitation products (next six panels). Consistent with the conclusions based on the CHIRPS product only, the results from the other rainfall products also show that the probability of drought occurrence in East Africa has decreased slightly from preindustrial to present day, and irrespective of whether variance adjustment has occurred (Fig. 2, all blue and black bars, with and without hatching). Future projections of drought likelihood do, however, vary depending on precipitation product used. For the mean-corrected GCM estimates, six out of seven rainfall product-corrected GCM projections give a slight decrease in drought occurrence likelihoods by the end of the 21st century. The exception is the TRMM-corrected GCMs, which suggest the drought probability will increase slightly by 2070-2100 and relative to the present day. For the likely more appropriate mean- and variance-corrected GCM estimates, then relative to present-day levels the GCM estimates corrected to the CHIRPS, ERA-interim, and TRMM products give an increase in future drought occurrence probability. However GPCP-, PREC/L- and CPC-corrected GCM estimates suggest the probability of drought occurrence will slightly decrease. This divergence is due to the strong differences in the climatological mean, SD and year 2016 ASO rainfall levels among the different precipitation products (Table S2).

As a sensitivity study, we also perform a bias correction based on each precipitation product but for the full ensemble of 37 GCM estimates together. That is, we combine all GCM present-day estimates into one single vector and calculate single overall $\mu$ and $\sigma$ values. All seven precipitation datasets are used to repeat the bias correction with similar methods to Eqs. (1) and (2). This approach implies that the probability of drought occurrence in East Africa has decreased slightly from pre-industrial to the end of the 21 st century, regardless of whether variance has been corrected (Fig. S1). However this approach should be viewed with caution, as making single bias corrections for all the GCMs combined neglects model differences, which are known to be large in precipitation projections (Collins et al., 2013).

Our results are broadly consistent with the recent analysis of Ethiopian drought projections by Philip et al. (2017), who also use observations to reduce the model uncertainty in GCM projections. They project future changes in drought by the use of only GCMs which can reproduce well the observed distribution of February to September climatological rainfall. They find that under RCP8.5 scenario there is no significant change in the likelihood of 2015 Ethiopian drought event. Although it is in many regards logical to exclude models that do not perform well for modelling the contemporary period, our approach is possibly more cautious. This is because there always remains a concern that a rejected model may hold important information about expected future changes, even if having strong biases in modelling the present day. Nev- 
ertheless, as a further sensitivity study, we also apply the same method as Philip et al. (2017) for our study region. This is with the CHIRPS dataset, and we place our findings in Fig. S2. The probability of 2016 ASO drought is based on rainfall projections from three models (i.e. CMCC-CM, GFDL-ESM2G and MPI-ESM-MR). They are the only models that match the climatology from CHIRPS product when using a Kolmogorov-Smirnov test, and at a significance level of 0.1 . The results are generally consistent with both the mean- and variance-corrected GCM results of Fig. 1d. That is, they indicate that the probability of drought occurrence in East Africa may increase slightly from present towards the end of the 21st century.

The multi-model ensemble forecast, corrected by the CHIRPS rainfall product and merging the individual forecasts with equal weights, shows that the East African mean ASO rainfall for 2070-2100 will increase significantly, compared with the present period 2001-2031 (Fig. 1d). It is these general increases that, even in conjunction with larger future distribution spreads, imply no massive increase of drought occurrence probability (insets, Fig. 1c, d). However in Fig. 3, we present for the individual models as well. Shown are changes in numbers of years of mean ASO rainfall falling below $40 \mathrm{~mm}$ per month (the CHIRPS 2016-based threshold). This is for the individual GCMs bias-corrected against present-day mean ASO rainfall only (top row), or additionally against SD (second row). Both rows illustrate some individual GCMs project quite substantial changes. We also show individual model percentage changes in mean (third row) and SD (bottom row) of ASO rainfall, for 31 years 2070-2100 compared to 2001-2031. Figure 3 shows 28 out of 37 model estimates for this region become wetter on average, and most models (i.e. 22 out of 37 models) exhibit increased distribution spreads reflected by raised SDs. Hence many models generally agree on the direction of these changes, but even then the magnitude of changes in rainfall remains uncertain.

Our analysis reveals that current understanding of how future climate change will impact on East Africa ASO drought risk remains uncertain. This is based on a relatively simple assessment of 37 climate models, each given equal weight but after being corrected by observation-based rainfall products. Different sources of uncertainty in drought prediction include the following: (1) the choice of bias correction methodology; (2) the choice of observational product used to correct bias in GCMs; and (3) the choice of GCMs used. Currently, for many geographical regions, GCM estimates of rainfall changes varies substantially across models (Knutti and Sedláček, 2013). Multi-model analyses such as ours therefore illustrate uncertainty associated with different model parameterisation or scheme describing rainfall features. However, to give more definitive answers, the climate research community may need to be confident enough to rank climate models based on performance to refine future projections (Knutti et al., 2017). Improving GCM projections will most likely need ongoing constraint of many model components. For East African rainfall predictions in particular, this needs to link to accurate forward projections of oceanic variability. Strong teleconnections are known to exist between El Niño-Southern Oscillation (ENSO) and East African rainfall (Segele et al., 2009; Gissila et al., 2004; Gleixner et al., 2017), and with longer-term fluctuations in Pacific sea surface temperatures, either increasing or decreasing rainfall (Funk et al., 2014; Liebmann et al., 2014; Gleixner et al., 2017). Larger ensembles of simulations by each model are also important, and especially when analysing the probability of extreme events. This enables a more complete sampling of probability distributions, describing more fully the internal variability of the climate system imposed over general climate changes. Some GCMs estimate an increase in future variability of East African ASO rainfall, and better knowledge of the magnitude of this is important. Significantly raised variability may cause a higher frequency of droughts, even if background trends are for higher mean rainfall levels. Other researchers also illustrate that any variability increases as well as mean changes have strong impacts on society (Brown and Lall, 2006). Furthermore, food and water availability in East Africa has multiple socio-economic drivers, alongside climatic influences (Little et al., 2001; Adhikari et al., 2015). Although here we have focused on climate model projections of the future, more holistic approaches will combine climate and crop impact modelling. The hope is that climate model predictions for East Africa will move towards a consensus on expected changes, therefore facilitating better protection and disaster preparedness against future famine.

Data availability. All CMIP5 data and all precipitation datasets are freely available from their respective host websites. CMIP5 data are downloaded from http://cmip-gw.badc.rl.ac.uk. Climate Hazards Group InfraRed Precipitation with Station data (CHIRPS) are from a global rainfall dataset, which was downloaded from ftp: //ftp.chg.ucsb.edu/pub/org/chg/products/CHIRPS-2.0. The alternative six climate datasets include (1) Climate Research Unit (CRU) TS v4.01 (http://data.ceda.ac.uk//badc/cru/data/cru_ts/cru_ts_4.01/; Harris et al., 2014); (2) the European Centre for Medium-Range Weather Forecasts Reanalysis (ERA) interim (http://apps.ecmwf. int/datasets/data/interim-full-daily/levtype=sfc/; Dee et al., 2011); (3) Global Precipitation Climatology Project (GPCP) v2.3 (https: //www.esrl.noaa.gov/psd/data/gridded/data.gpcp.html; Adler et al., 2003); (4) Precipitation Reconstruction Land (PREC/L, https:// www.esrl.noaa.gov/psd/data/gridded/data.precl.html; Chen et al., 2002); (5) Climate Prediction Center (CPC, https://www.esrl.noaa. gov/psd/data/gridded/data.cpc.globalprecip.html; Xie and Arkin, 1997); (6) The Tropical Rainfall Measuring Mission (TRMM, https: //pmm.nasa.gov/trmm; Huffman et al., 2007).

Code availability. The Matlab scripts leading to any of the diagrams are available on request to Hui Yang (yang_hui@ pke.edu.cn). 


\section{The Supplement related to this article is available online at https://doi.org/10.5194/nhess-18-491-2018- supplement.}

Competing interests. The authors declare that they have no conflict of interest.

Acknowledgements. Hui Yang gratefully acknowledges funding from the China Scholarship Council, and Chris Huntingford acknowledges the NERC CEH National Capability fund. The authors acknowledge the World Climate Research Programme's Working Group on Coupled Modelling, which is responsible for CMIP, and we thank the climate modelling groups for producing and making available their model output. We also acknowledge the re-analysis products of the European Centre for Medium-Range Weather Forecasts.

Edited by: Bruno Merz

Reviewed by: two anonymous referees

\section{References}

Adhikari, U., Nejadhashemi, A. P., and Woznicki, S. A.: Climate change and Eastern Africa: A review of impact on Major Crops, Food Energy Secur., 4, 110-132, 2015.

Adler, R. F., Huffman, G. J., Chang, A., Ferraro, R., Xie, P., Janowiak, J., Rudolf, B., Schneider, U., Curtis, S., Bolvin, D., Gruber, A., Susskind, J., and Arkin, P.: The Version 2 Global Precipitation Climatology Project (GPCP) Monthly Precipitation Analysis (1979-Present), J. Hydrometeorol., 4, 1147-1167, 2003.

Angélil, O., Perkins-Kirkpatrick, S., Alexander, L. V., Stone, D., Donat, M. G., Wehner, M., Shiogama, H., Ciavarella, A., and Christidis, N.: Comparing regional precipitation and temperature extremes in climate model and reanalysis products, Weather Clim. Extremes, 13, 35-43, 2016.

Brown, C. and Lall, U.: Water and economic development: The role of variability and a framework for resilience, in: Natural Resources Forum, Blackwell Publishing Ltd., 30, 306-317, 2006.

Chen, M., Xie, P., Janowiak, J. E., and Arkin, P. A.: Global Land Precipitation: A 50-yr Monthly Analysis Based on Gauge Observations, J. Hydrometeorol., 3, 249-266, 2002.

Collins, M., Knutti, Arblaster, R. J., Dufresne, J.-L., Fichefet, T., Friedlingstein, P., Gao, X., Gutowski, W.J., Johns, T., Krinner, G., Shongwe, M., Tebaldi, C., Weaver, A. J., and Wehner, M.: Long-term Climate Change: Projections, Commitments and Irreversibility, in: Climate Change 2013: The Physical Science Basis. Contribution of Working Group I to the Fifth Assessment Report of the Intergovernmental Panel on Climate Change, edited by: Stocker, T. F., Qin, D., Plattner, G.-K., Tignor, M., Allen, S. K., Boschung, J., Nauels, A., Xia, Y., Bex, V., and Midgley, P. M., Cambridge University Press, Cambridge, United Kingdom and New York, NY, USA, 2013.

DEC, Disasters Emergency Committee: available at: https://www. dec.org.uk/splash/africa (last access: 5 February 2018), 2017.
Dee, D. P., Uppala, S. M., Simmons, A. J., Berrisford, P., Poli, P., Kobayashi, S., Andrae, U., Balmaseda, M. A., Balsamo, G., Bauer, P., Bechtold, P., Beljaars, A. C. M., van de Berg, L., Bidlot, J., Bormann, N., Delsol, C., Dragani, R., Fuentes, M., Geer, A. J., Haimberger, L., Healy, S. B., Hersbach, H., Hólm, Isaksen, L., Kållberg, P., Köhler, M., Matricardi, M., McNally, A. P., Monge-Sanz, B. M., Morcrette, J.-J., Park, B.-K., Peubey, C., de Rosnay, P., Tavolato, C., Thépaut, J.-N., and Vitart, F.: The ERA-Interim reanalysis: Configuration and performance of the data assimilation system, Q. J. Roy. Meteor. Soc., 137, 553-597, 2011.

Harris, I. P. D. J., Jones, P. D., Osborn, T. J., and Lister, D. H.: Updated high-resolution grids of monthly climatic observationsthe CRU TS3.10 Dataset, Int. J. Climatol., 34, 623-642, 2014.

Huffman, G. J., Adler, R. F., Bolvin, D. T., Gu, G., Nelkin, E. J., Bowman, K. P., Hong, Y., Stocker, E. F., and Wolff, D. B.: The TRMM Multi-satellite Precipitation Analysis: Quasi-Global, Multi-Year, Combined-Sensor Precipitation Estimates at Fine Scale, J. Hydrometeorol., 8, 38-55, 2007.

Funk, C., Hoell, A., Shukla, S., Bladé, I., Liebmann, B., Roberts, J. B., Robertson, F. R., and Husak, G.: Predicting East African spring droughts using Pacific and Indian Ocean sea surface temperature indices, Hydrol. Earth Syst. Sci., 18, 4965-4978, https://doi.org/10.5194/hess-18-4965-2014, 2014.

Funk, C., Peterson, P., Landsfeld, M., Pedreros, D., Verdin, J., Shukla, S., Husak, G., Rowland, J., Harrison, L., Hoell, A., and Michaelsen, J.: The climate hazards infrared precipitation with stations-a new environmental record for monitoring extremes, Sci. Data, 2, 150066, https://doi.org/10.1038/sdata.2015.66, 2015.

Gissila, T., Black, E., Grimes, D. I. F., and Slingo, J. M.: Seasonal forecasting of the Ethiopian summer rains, Int. J. Climatol., 24, 1345-1358, 2004.

Gleixner, S., Keenlyside, N., Viste, E., and Korecha, D.: The El Niño effect on Ethiopian summer rainfall, Clim. Dynam., 49, 1865-1883, 2017.

Jeon, S., Paciorek, C. J., and Wehner, M. F.: Quantile-based bias correction and uncertainty quantification of extreme event attribution statements, Weather Clim. Extremes, 12, 24-32, 2016.

Knutti, R. and Sedláček, J.: Robustness and uncertainties in the new CMIP5 climate model projections, Nat. Clim. Change, 3, 369373, 2013.

Knutti, R., Sedláček, J., Sanderson, B. M., Lorenz, R., Fischer, E. M., and Eyring, V.: A climate model projection weighting scheme accounting for performance and interdependence, Geophys. Res. Lett., 44, 1909-1918, 2017.

Little, P. D., Smith, K., Cellarius, B. A., Coppock, D. L., and Barrett, C.: Avoiding disaster: diversification and risk management among East African herders, Dev. Change., 32, 401-433, 2001.

Love, R.: Economic Drivers of Conflict and Cooperation in the Horn of Africa, Chatham House Briefing Paper, December, available at: www.chathamhouse.org/publications/papers/view/ 109208 (last access: 18 April 2012), 2009.

Masih, I., Maskey, S., Mussá, F. E. F., and Trambauer, P.: A review of droughts on the African continent: a geospatial and long-term perspective, Hydrol. Earth Syst. Sci., 18, 3635-3649, https://doi.org/10.5194/hess-18-3635-2014, 2014.

Philip, S., Kew, S. F., van Oldenborgh, G. J., Otto, F., O’Keefe, S., Haustein, K., King, A., Zegeye, A., Eshetu, Z., Hailemariam, 
K., Singh, R., and Jjemba, E., Funk, C., and Cullen, H.: Attribution analysis of the Ethiopian drought of 2015, J. Climate, https://doi.org/10.1175/JCLI-D-17-0274.1, online first, 2017.

Segele, Z. T., Lamb, P. J., and Leslie, L. M.: Large-scale atmospheric circulation and global sea surface temperature associations with Horn of Africa June-September rainfall, Int. J. Climatol., 29, 1075-1100, 2009.

Sippel, S., Otto, F. E. L., Forkel, M., Allen, M. R., Guillod, B. P., Heimann, M., Reichstein, M., Seneviratne, S. I., Thonicke, K., and Mahecha, M. D.: A novel bias correction methodology for climate impact simulations, Earth Syst. Dynam., 7, 71-88, https://doi.org/10.5194/esd-7-71-2016, 2016.
Taylor, K. E., Stouffer, R. J., and Meehl, G. A.: An overview of CMIP5 and the experiment design, B. Am. Meteorol. Soc., 93, 485-498, 2012.

von Grebmer, K., Bernstein, J., Nabarro, D., Prasai, N., Amin, S., Yohannes, Y., Sonntag, A., Patterson, F., Towey, O., Thompson, J.: Global Hunger Index: Getting to Zero Hunger. Welthungerhilfe, International Food Policy Research Institute, and Concern Worldwide, Bonn, Washington, DC, and Dublin, 2016.

Xie, P. and Arkin, P. A.: Global precipitation: A 17-year monthly analysis based on gauge observations, satellite estimates, and numerical model outputs, B. Am. Meteorol. Soc., 78, 2539-2558, 1997. 